\title{
Os adolescentes infratores e o empobrecimento da rede social quando do retorno à comunidade
}

\author{
Adolescent transgressors and the weakening of their social network \\ when they return to the community
}

Bianca de $\mathrm{M}$ oraes Branco ${ }^{1}$

Adriana Wagner ${ }^{1}$

${ }^{1}$ Universidade Federal da Bahia, Salvador, Brasil

Endereço para

correspondêencia:

UniversidadeFederal da

Bahia. Av. Reitor Miguel

Calmon, $s / n$, Vale do

Canela, Salvador, BA, 40 110-905.

bmbranco@yahoo.com.br

${ }^{2}$ Universidade Federal do

Rio Grande do Sul,

Instituto de Psicologia do

Desenvolvimento eda

Personalidade.
Abstract The goal of this case study was to understand the success (or failure) of the ICPAE initiative (from Portuguese: Intern with possibility of External Activity) of the Foundation for Social-Educative Services of Rio Grande do Sul in the light of the characteristics of the social network of these young transgressors and of their perception of the functioning of their family. Five adolescents were investigated in the beginning and in theend of the ICPAE experience. We used a social network map, and for evaluating the functioning of the family we used the GARF scale (Global Assessment of Relational Functioning Scale). It was observed that the social network of these youths tended to be poorer than in the first map and also that they were centered on the family. The second ICPAE assessment revealed significantly worse results in comparison to the first, except in the case of one adolescent who had the most complete social network in both moments. Key words Adolescent, Family, Transgressor, Social network
Resumo 0 objetivo deste estudo foi compreender 0 sucesso ou não do cumprimento da medida deICPAE (Interno com Possibilidade de Atividade Externa) na Fase-RS (Fundação de A tendimento Sócio-Educativo do Rio Grande do Sul), à luz das características da rede social desses jovens infratores, bem como da percepção do funcionamento de sua família. Foram investigados quatro adolescentes, no começo e ao final do cumprimento desta medida, através da metodologia de estudo de caso. Utilizou-se o mapa da rede social e, para a avaliação do funcionamento familiar, foi utilizada a escala GARF (Global Assessment of Relational Functioning Scale). H ouveuma tendência geral de empobrecimento da rede social desses jovens em relação ao primeiro mapa, bem como de centralização na família. A segunda avaliação do cumprimento da medida de ICPAE teveuma piora significativa em relação à primeira, excetuando-se 0 adolescente que teve a rede social mais completa, em ambos os momentos.

Palavras-chave Adolescente, Família, Infrator, Rede social 
Introdução

No Rio Grande do Sul, os adolescentes infratores são julgados por um juiz da Infância e da Adolescência e podem ser condenados à medida sócioeducativa, a ser cumprida na Fundação de Atendimento Sócio-Educativo (Fase). A Fase-RS éórgão do Governo do Estado, vinculada à Secretaria do Trabalho, Cidadania e Assi stência Social. Foi criada a partir da Lei Estadual $\mathrm{n} 011.800$, de 28 demaio de 2002, e do Decreto Estadual no 41.664 - Estatuto Social, de 6 de junho de 2002, consolidando 0 processo de reordenamento institucional iniciado com o advento do Estatuto da Criança e do Adolescente(Lei 8.069/90), o qual também provocou o fim da antiga Fundação do Bem-Estar do M enor (Febem). A Fase conta com equipes interdisciplinares, formadas por monitores, assistentes sociais, pedagogos, professores, psicólogos, médicos clínicos, dentistas, médicos psiquiatras, enfermeiros etécnicos de enfermagem. 0 programa da Fase está organizado em dois eixos: o processo de execução de internação e o de semiliberdade. Dentro da execução da internação, o adolescente pode cumprir a medida de ICPAE - interno com possibilidade de atividade externa - ou de ISPAE - interno sem possibilidade de atividade externa.

$O$ objetivo deste estudo é avaliar os adolescentes durante o cumprimento da medida de ICPAE, isto é, quando eles, geralmente após um período de reclusão completa na Fase, começam a ter direito a saídas para casa nos finais de semana, bem como a ter a possibilidade de trabalhar e de estudar na comunidade. Apesar de se constituir em um momento de ampliação das oportunidades, também é aquele em que a capacidade de autocrítica e de autocontrole faz-se mais necessária. E, ainda que, durante a internação fechada, se saiba (através dos funcionários da Fase) como estes jovens estão, o que estão fazendo, o que estão estudando, como estão se relacionando, pouco se sabe de suas condutas edificuldades duranteeste período deICPAE.

Para avaliar o impacto desta medida nesses jovens, partiu-se de uma revisão teórica sobre a delinqüência juvenil. A partir desta, ficou evidenteque al gumas características familiares têm sido consideradas preditoras de conduta pró-social ou protetora do ato infracional pelos adolescentes. São elas: a estrutura hierárquica definida ${ }^{1}$, a boa qualidade de relação entre os pais ${ }^{2}$, o estabelecimento de um padrão de apego seguro pelo jovem ${ }^{3,4}$, a boa qualidade de comunicação do jovem com os paise entre el es ${ }^{1}$, bem como menos atitudes autoritárias pelos progenitores ${ }^{5,6}$.
No entanto, a importância da redesocial (além da família) desses jovens neste comportamento também tem sido evidenciada em alguns estudos. Nessa rede, a influência dos pares tem relevante importância na prática do ato infracional ${ }^{5-9}$.

Também parece claro que a delinqüência está imbricada com outras questões de gravidade, como a baixa escolaridade ${ }^{7}$ e 0 uso de drogas $5^{6,9,10}$. Quanto à importância da rede social, encontrouse que estar empregado ou na escola, no início da idade adulta, são fatores protetores da recaída no ato infracional ${ }^{6}$.

Partindo desses pressupostos empíricos, tornou-se evidente a importância de se comparar 0 início e o final da medida deICPAE quanto às características da redesocial dos adolescentes, bem como quanto à percepção do funcionamento familiar por esses jovens, compreendendo o sucesso ou fracasso de seu cumprimento à luz dessas variáveis.

\section{Método}

O método utilizado nesta pesquisa foi o estudo de caso individual, proposto por Stake ${ }^{11}$, que busca, especialmente, o que pode ser aprendido a partir do caso singular. Este método busca retratar a realidade de forma profunda e interpretá-la dentro deum contexto; utiliza uma variedade de fontes de informação, procurando representar os diferentes pontos de vista presentes numa situação social. Portanto, foram feitas articulações entre a GARF, a construção dos mapas da rede social e os dados de avaliação da medida deICPAE, de forma que esses instrumentos se constituíssem em óticas diferentes e complementares do mesmo objeto. Esses dados foram coletados em dois momentos: no começo e ao final da medida de ICPAE.

\section{Participantes}

Foram estudados quatro adolescentes infratores que estavam cumprindo algum período dos dois primeiros meses da medida de ICPAE, na FaseRS e que aceitaram participar da pesquisa. Buscou-seestudar jovens quefossem identificados pela equipe como singulares e diferentes entre si, seja por sua história familiar, pelo ato infracional ou pelo comportamento dentro da instituição, deforma a contemplar a maior diversidade possível da vivência dessefenômeno.

\section{Instrumentos}

Foram utilizados os instrumentos de avaliação 
da medida de ICPAE, versão do adolescente e da monitoria/equipe técnica, 0 mapa da rede social ${ }^{12}$, a entrevista semi-estruturadaa ${ }^{13}$ e a GARF ${ }^{14}$ :

. GARF: avaliou essencial mentea satisfação das necessidades dos sujeitos (na família), a flexibilidade de papéis, os conflitos, a hierarquia, o reconhecimento das características pessoais dos membros e a expressão de sentimentos. A GARF éuma escala diagnóstica do funcionamento familiar consagrada na literatura internacional e validada para 0 uso em nosso meio ${ }^{15}$. O s escores da GARF estão distribuídos em quatro categorias: de 81 a 100 funcionamento familiar bom, de 61 a 80 - padrão de relacionamento familiar de alguma forma insatisfatório, 41 a 60 - família com predomínio de relações insatisfatórias, 21 a 40 - família claramente disfuncional ${ }^{16}$.

- M apa da rede social: consiste em três círculos concêntricos divididos em quatro quadrantes: família, amigos, escola-trabalho e comunidade. 0 núcleo do círculo representa o sujeito, o primeiro círculo e menor, indica a proximidade e a importância que 0 adolescente dá aos sistemas ali existentes; o segundo círculo se constitui por pessoas que têm menor proximidade e importância para ele; finalmente, no terceiro círculo, colocam-se as pessoas que compartilham com o adolescente de forma mais distante. Foram utilizados adesivos, cada um representando um indivíduo ou instituição, já em formatos redondos ( para as mulheres) e quadrados (para os homens) ou de triângulos (instituições).

. Entrevista semi-estruturada: foi proposta por $M$ eneses ${ }^{13}$, e suas questões visam a esclarecer categorias específicas da rede social. Para a dimensão estrutural, as categorias são o tamanho da rede, a densidade, a distribuição, a dispersão e a homogeneidade. Para a dimensão funcional, são a companhia social, o apoio emocional, o guia cognitivo, a regulação social, a ajuda material e de serviços e 0 acesso a novos contatos.

- Avaliação da medida de ICPAE: foi desenvolvida para esta pesquisa e considera como variáveis os atrasos no retorno à Fase, fuga, necessidade de medidas disciplinares, uso de drogas, reincidência no ato infracional, o comprometimento com a escola e o comprometimento com atividades laborais. Essas variáveis foram obtidas do programa de inserção comunitária eacompanhamento de egressos da FEBEM/RS, elaborado em $2001^{17}$. A nota deste instrumento pode variar entre 8 e 32 , sendo que32 éa melhor nota de cumprimento da medida e 8, a pior. Para fins de padronização, para este estudo, estipulou-se que as notas de 8 a 16 seriam ruins, de 17 a 24, limítrofes e de 25 a 32, boas.

\section{Procedimentos de coleta de dados}

A pesquisa foi autorizada pela presidência da Fase-RS, pelo Juizado da Infância e da Juventudee aprovada pelo Comitê de Ética da PU CRS. Os dados foram coletados em uma sala da própria Fase e os adolescentes foram orientados a serem sinceros e tranqüilizados quanto ao sigilo desses dados eà não utilização desses pelo juiz. Foram coletados dados da história do jovem e, com base nesta, 0 funcionamento familiar recebeu uma nota, conforme a GARF, por entrevistador capacitado.

Com vistas à avaliação da rede social, os adolescentes foram convidados a criar a sua rede social. Eles tiveram à disposição os adesivos e o mapa, proposto por Sluzki ${ }^{12}$, e foram questionados com as seguintes perguntas: "Quem são as pessoas importantes na tua vida?", "Com quem podes contar?", conforme sugestão de Sluzki ${ }^{12}$. Essa etapa foi gravada em fitas de áudio, já que foi um período decriação do adolescenteem queelefez colocações verbais, à medida que foi colando os adesivos no mapa. Terminado o mapa, foram feitas as perguntas do questionário proposto por $\mathrm{Meneses}^{13}$, de forma a enriquecer o mapa e torná-lo mais fidedigno. As perguntas eram tais como "o que você acha do número depessoas quecompõem sua rede social?", para avaliar tamanho; ou "o que você acha de como estão distribuídas as pessoas nos quadrantes?", para avaliar distribuição, etc. Ou, com relação à dimensão funcional, perguntas como "quando você tem vontade de sair, a quem convida?", para avaliar companhia social.

0 instrumento de avaliação da medida de ICPAE foi aplicado levando em consideração, além da percepção do próprio interno, a de um representante da equipe técnica e da monitoria. Esses representantes foram escolhidos conforme a disponibilidade e a vontade desses profissionais; priorizaram-secomo representantes aqueles que afirmaram conhecer bem o jovem e ter maior tempo de convívio com o mesmo. A equipe técnica éuma equipe formada por psicólogos, assistentes sociais e educadores e é responsável pela realização dos relatórios avaliativos dos adolescentes a cada audiência, bem como pelo contato com as famílias, com as escolas e pelas visitas domiciliares. Os monitores são funcionários que convivem no dia-adia com os menores, colocando limites e estabelecendo medidas disciplinares. Essas três visões foram levadas em consideração, tendo em vista que a visão única do adolescenteseria de pouca confiabilidade, na medida em que eles poderiam temer que estas revelações viessem a julgamento (mesmo orientados do contrário). 
No segundo momento, ao final da medida de ICPAE, 0 adolescente foi convidado a confeccionar um novo mapa da sua rede social. Também foi feita uma nova avaliação da sua medida de ICPAE, solicitando-se que refletisse sobre as diferenças entre os dois momentos.

\section{Resultados}

Os dados da pesquisa serão apresentados caso a caso e a ordem de apresentação será: o resumo da história do adolescente, a avaliação do funcionamento familiar, as notas quanto ao sucesso da medida de ICPAE no primeiro e no segundo momento e os mapas da rede social, também de ambos os momentos. Todos os nomes dos sujeitos foram alterados para manter o sigilo.

\section{Adolescente Eduardo}

0 adolescente tem 18 anos e estudou até 010 ano do ensino médio. Teve várias repetências escolares, segundo ele, devido a constantes mudanças de cidade da família. Afirma que começou a traficar aos 15 anos, por "curiosidade" e "adrenalina". A família, segundo relato de Eduardo, teria descoberto suas atitudes ainda em 2003, quando ele re cebeu medidas de liberdade assistida (LA) e programa de serviço à comunidade (PSC) por furto $e$ agressão.

A nota GARF de avaliação do funcionamento familiar ficou em 55, isto é, uma família com momentos de satisfação, mas com predomínio de relações insatisfatórias e de comunicação inviabilizada por conflitos não resolvidos. A pesar de haver al gum calor e apoio entre os membros, há o sentimento, em Eduardo, de ser o preterido na família.

Avaliações da medida de ICPAE de Eduardo No primeiro momento, Eduardo avaliou sua medida de ICPAE com nota 25, a equipe técnica, com nota 32 e a monitoria, 26; portanto, ele teve um "bom" resultado em todas as avaliações. Ao final do período, Eduardo avaliou sua medida de ICPAE com nota 21 , a equipetécnica, com nota 27 e a monitoria, 24. Portanto, todos os três deram uma nota inferior ao final da medida, sendo que o adolescente e a monitoria consideraram o desempenho do jovem "limítrofe", só a equipe técnica o considerando "bom".

Os mapas da rede social de Eduardo

Nos mapas de Eduardo, o tamanho se manteve praticamente o mesmo, sendo que no primeiro ha- via seis pessoase, no segundo, sete. Também semanteve um predomínio de pessoas no quadrante "família", com poucas pessoas no quadrante "amigos". A psiquiatra da instituição perdeu espaço no segundo mapa, bem como o primo J. Jáa irmã C., a tia eo pai foram lembrados, apenas no segundo momento, ainda que o pai, como um "amigo distante".

Em ambas as avaliações, Eduardo considerou sua rede "pequena", sentindo falta da escola (em greve) e do trabalho (que ainda não tinha) no primeiro momento. No segundo, relatou sentir-se sozinho, "como se ainda estivesse preso". Ainda que no segundo momento estivesse trabalhando, não quis preencher o quadrante "trabal ho", afirmando não gostar de seu trabalho. Quando questionado, no primeiro momento, sobre o que achava da distribuição das pessoas em sua rede, afirmou sentir falta da "comunidade". Quanto à "dispersão", no primeiro momento, se sentia próximo fisicamente da namorada, da mãe, do irmão e do primo J.; no segundo, a mãe e a namorada (aqui chamada esposa) permaneceram, mas o primo J. foi substituído pelo irmão M. Quanto à "homogeneidade", no começo, ele se considerava parecido com o primo J., mas, ao final, é a esposa quem surge como a mais parecida com ele.

A "companhia social", que era também exercida pelo primo J., passa a ser exercida por "amigos" que ele não julgou suficientemente importantes para inserir em seu mapa. 0 apoio emocional, inicialmente, era dado pela mãee pelo irmão, mas, ao final, ele considera não o ter de ninguém.

0 papel de "guia cognitivo e conselheiro" passa da mãe e da monitoria (embora não tenha querido inserir esta última no mapa) para a esposa. A regulação social, no começo da medida, era dada pelos remédios e pela psiquiatra da instituição, mas, no segundo momento, passa a ser tarefa da esposa e da mãe. A "ajuda material e de serviços" era dada, inicialmente, pelo irmão F. e pelo primo J., mas passa a ser fornecida pela mãe e esposa. A tia foi lembrada, nos dois momentos, como um contato religioso.

\section{Adolescente Tadeu}

Tadeu tem 18 anos e estudou até $01^{\circ}$ ano do $2^{\circ}$ grau. Seus pais se separaram há mais de dez anos. 0 pai bebia e era muito agressivo, tanto com a esposa, quanto com seus filhos. Aos 14 anos, 0 jovem teve de cumprir PSC, em LA, por porte ilegal dearma. Aos 15 anos, el efoi encaminhado para um abrigo, através da Justiça, por encontrar-se em situação de conflitos agressivos com seu pai e de risco de morte na comunidade (tinha sido acu- 
sado de queimar uma casa). No entanto, neste período em que morou no abrigo, não ia ao trabalho, gazeava aulas, não visitava os familiares, fugia, usava drogas.

A nota GARF do funcionamento familiar foi 30, caracterizando, portanto, uma família claramentedisfuncional, com presença de poder tirânico ou muito negligente, contato afetivo raramente satisfatório e conflitos não resolvidos.

Avaliações da medida de ICPAE de Tadeu

No primeiro momento, Tadeu avaliou sua medida de ICPAE com nota 26. Já a equi pe técnica deu nota 27, e a monitoria, 21. Portanto, ele e a equipe técnica consideraram que ele estava tendo uma "boa" medida; já a monitoria a considerou "limítrofe". No segundo momento, Tadeu avaliou sua medida com nota 24, a equipe técnica, com nota 23 ea monitoria, com nota 29 . Portanto, houve uma inversão e agora a equipe técnica, bem como o adolescente, passam a considerar seu desempenho "limítrofe", enquanto a monitoria passa a achá-lo "bom".

Os mapas da rede social de Tadeu

Há uma diferença importanteentre o primeiro e o segundo mapa de Tadeu. No primeiro, ainda que seja um mapa pobre, ele conta com sete integrantes e ocupa dois quadrantes, "família" e "amigos". No segundo, mantêm-se apenas a mãe e a esposa. Os monitores da Fase, o irmão da Igreja, bem como a cunhada, perdem espaço no mapa.

Quanto à "distribuição", embora o primeiro mapa tenha sido mais completo, ele, no início da medida, reclama o fato de a comunidade estar distante, de não ter amigos, nem trabalho, nem escola (em greve). Ao final da medida, apesar de ter apenas duas pessoas em sua rede, ele afirma não sentir falta de ninguém e sentir-se mais próximo da comunidade, masnão inclui ninguém nestequadrante. Quanto à "dispersão", ele, inicialmente, diz sentir-se próximo fisicamente da mãe e da namorada, mas depois diz sentir a mãe distante, em função de morar em outra vila. Quanto à "homogeneidade", a mãe se estabel ece como a mais parecida com ele, "braba, irritada e nervosa", em ambos os momentos.

A "companhia social" é a esposa no começo e ao final da medida. Afirma, nos dois momentos, não ter amigos. 0 quesito "apoio emocional" não era preenchido por ninguém e a esposa passa a exercêlo no decorrer da medida. A "conselheira" deixa de ser a mãe e a monitoria e passa a ser a esposa. A "regulação social" era inicialmente um papel da monitoria, masa esposa o assume. A "aju- da material" que era feita pela mãe e pela cunhada agora não é feita por ninguém. 0 irmão da I greja foi lembrado inicialmente como um contato religioso, mas ele considera não ter al guém queexerça o papel de "acesso a novos contatos" ao final da medida.

Adolescente Júnior

Júnior tem 18 anos e cursa $01^{\circ}$ ano do $2^{\circ}$ grau. 0 adolescente afirma que está envolvido com 0 tráfico desde os 11 anos, mas que a mãe só teria descoberto quando ele já estava com 15 anos. Seu primeiro ingresso na Fase foi aos 16 anos, quando recebeu PSC de 24 semanas por tráfico. Retornou à Fase em 2005, por porte ilegal de arma e de entorpecentes.

Através da GARF, o funcionamento familiar recebeu nota 45, isto é, uma família com momentos de satisfação, mas com predomínio de relações insatisfatórias e de comunicação inviabilizada por conflitos não resolvidos.

Avaliações da medida de ICPAE de Júnior No início da ICPAE, Júnior avaliou a sua medida com nota 30 , enquanto a equipe técnica deu nota 32 , ea monitoria deu nota 21 , mostrando um desempenho "bom" conformeele próprio ea equipe técnica e um desempenho "limítrofe", segundo a monitoria. No entanto, todos os três, ao reavaliar seu desempenho, ao final da medida, deram notas significativamente mais baixas, sendo que Júnior se deu nota 22, quecorrespondea uma nota "limítrofe", a monitoria deu nota 17, também "Iimítrofe" ea equipetécnica deu nota 16, considerada "ruim".

Os mapas da rede social de Júnior

Há um evidente empobrecimento do mapa da rede social deste jovem, ao longo de sua medida.

Ainda que, inicialmente, el etenhainserido indivíduos nos quadrantes "família" e "amigos", totalizando dez membros, ao final, seu mapa contabiliza apenas duas pessoas, sua mãe e sua namorada, ambas inseridas no quadrante "família".

Júnior terminou a confecção do primeiro mapa o julgando com "grandenúmero de pessoas". Quando questionado quanto ao "tamanho" do seu mapa no segundo momento, ele disse "está bom assim". Q uanto à "distribuição" das pessoas nos mapas, ele disse, inicialmente, achar "bem distribuído" e, ao final, afirmou não se importar com isso. Sentia-se próximo, fisicamente, das pessoas do mapa, em ambos os momentos. Ele se considerava, no come ço, parecido com a irmã D. e diferente da mãe, em 
termos de temperamento. Já na segunda avaliação, se disse parecido com sua mãe e diferente de sua namorada. Revelou-se muito confuso nesta avaliação da "homogeneidade" da rede.

As "companhias sociais" de Júnior eram os amigos e, no decorrer da medida, ele disse não mais as ter. 0 "apoio emocional" é dado, primeiramente, pela mãe, depois passa a ser papel da namorada. A "conselheira" é inicialmente a mãe, mas, no segundo momento, ele disse não pedir conselhos a ninguém. A "regulação social" não é exercida por ninguém, apenas por ele mesmo, nos dois momentos.

A "ajuda material" vem, em princípio, dos amigos e a "ajuda de serviços" do irmão e da mãe, mas, ao final, ele considera não ter ninguém com quem contar nestes quesitos. 0 "acesso a novos contatos", embora exercido inicialmente pela família e pelos amigos, não éfacilitado por ninguém ao final da medida.

\section{0 adolescente Bernardo}

Bernardo tem 18 anos eparou de estudar na $8^{a}$ série do 10 grau. Repetiu a $1^{a \underline{a}}$ série, por ser muito "tímido", e a 3ạ série, porque "não prestava atenção". Aos oito anos, teve de interromper os estudos para trabalhar com seus pais na lavoura. Ele afirmou que, com 11-12 anos, começou a se revoltar com o pai, porque trabalhava para ajudá-lo, mas o pai se mostrava sempre insatisfeito com o queelefazia, o criticava enão o recompensava pelo seu esforço. Teve outros trabal hos e, com 16 anos, começou a roubar. Em 2005, ingressou na Fase por roubo qualificado.

A família recebeu uma nota de funcionamento 61. Assim, o padrão de relacionamento familiar éde alguma forma insatisfatório, mas há resolução sem grandes frustrações e conflitos para os problemas e presença de relações afetivas de amor e respeito.

Avaliações da medida de ICPAE de Bernardo Inicialmente, Bernardo avaliou sua medida de ICPAE com nota 29, a monitoria deu nota 31 e a equipe técnica, 32; portanto, as três notas são compatíveis com um "bom" cumprimento de medida. As notas permaneceram praticamente as mesmas, ao final da medida, sendo que Bernardo se deu nota 28, etanto a monitoria como a equipe técnica deram 32; portanto, mantiveram-se todas as três notas "boas".

Os mapas da rede social de Bernardo

Bernardo foi o adolescentequemostrou o mapa mais completo, do início ao final da medida, com doze integrantes na primeira entrevista e nove, na segunda. Foi o único adolescente que preencheu outro quadrante além do "família" e "amigos", inserindo, nos dois momentos, instituições ou pessoas no quadrante "comunidade". Foi o único também a lembrar de inserir instituições e que acrescentou no mapa, deforma espontânea, a Fase. Além disso, Bernardo foi o único a manter representantes da Fase em seu mapa ao final da medida.

Ele, como a maioria dos internos pesquisados, disse, inicialmente, querer poder contar com uma rede maior. Depois, percebeu que a rede havia se reduzido, e disse ter se arrependido de ter contado com algumas pessoas que o decepcionaram. 0 Bernardo considerou boa a distribuição de seu mapa. Via-se próximo fisicamente dos pais e afastado da irmã e da cunhada e, ao final, mantinha esta impressão da irmã e da cunhada e se ressentia de estar fisicamente afastado também da psiquiatra da instituição, bem como da filha, que descobriu ter durante a medida. Acredita ser diferente da família, e afirma que eles "fogem dos problemas". No entanto, dá a impressão, a partir de seu discurso que, na verdade, a família seria mais resignada e aceitaria melhor que ele as próprias dificuldades. No segundo momento, se diz identificado com o irmão V., de dois anos, com a filha, de um ano, e com um vizinho que, como ele, já esteve preso, mas que, há mais de dez anos, abandonou o crime.

As companhias sociais foram, inicialmente, os amigos J. e W., mas, ao final da medida, ele nega que alguém exerça este papel. 0 "apoio emocional" era dado pelo monitor G. e passa a ser papel do irmão V. $O$ "conselheiro", inicialmente, também era o monitor G., mas ele coloca, na segunda entrevista, Deus e a psiquiatra da instituição como exercendo esta função. Primeiramente, el edissenão precisar de um "regulador social", mas ao final da medida, afirma que quem o auxilia neste aspecto é Deus ea mãe. A "ajuda material" era fornecida pela mãe e a "ajuda de serviços" pela cunhada, mas, posteriormente, seu irmão K. é o responsável por esta ajuda. 0 "acesso a novos contatos" se dava através do amigo D. e da mãe, mas, por fim, ele acredita que se dê pela sua filha.

\section{Análisedosresultados}

Avaliando os resultados de forma comparativa e com vistas a uma maior compreensão deste fenômeno, nos quatro casos estudados, percebe-se que quase todas as redes se reduziram de tamanho. No início da medida, o total de membros dos mapas variaram entre seis e doze, o que é baixo 
comparando-se com os mapas da rede social obtidos por Ceolin 7 , constituídos por doze a 32 membros. No entanto, a amostra de Ceolin ${ }^{7}$ foi de adolescentes infratores que cumprem PSC, sem restrição da li berdade, do quese poderia hipotetizar que a restrição da liberdade acaba por reduzir o tamanho da rede social, o que parece razoável. Contudo, surpreendentemente, excetuando-se o caso de Eduardo, os mapas de rede reduziram-se de tamanho, ao final da medida de ICPAE, para dois a novemembros. Os próprios jovens explicaram este achado alegando terem se decepcionado com as pessoas em quem confiavam. Sentiam-se arrependidos por terem sido sinceros e por terem solicitado apoio de algumas pessoas. Uma vez que houve uma redução do tamanho da rede ao longo do movimento de saída da instituição para a comunidade, o mais provável é que haja, neste momento, a ruptura de um processo de idealização do externo, processo este desencadeado pelo forçado afastamento da convivência social.

Nenhum dos quatro adolescentes avaliados preencheu o quadrante "trabalho e escola", em nenhum dos momentos. Os adolescentes justificaram estes achados, no primeiro momento, dizendo que, como as escolas estavam em greve, eles não estavam tendo aulas. No segundo momento, justificaram dizendo não estarem estudando, visto terem trabalho; ou não julgarem a escola suficientemente importante para incluí-la, mesmo estudando.

Quanto ao trabalho, no começo da medida, afirmaram não estarem trabalhando, o que pode ser compreendido pelo fato de terem progredido para ICPAE recentemente e porque, antes, estavam totalmente fechados na instituição, o que inviabilizava o trabalho. No entanto, no segundo momento, três deles estavam trabalhando e mesmo assim não incluíram o trabal ho em seus mapas, afirmando ou não gostarem do trabalho, ou não o considerarem suficientementeimportante para incluí-lo.

A não-centralização do mapa da rede social e uma relação próxima e direta entre seus membros seriam indicadores de uma maior prontidão dessa rede, no sentido de prevenir problemas comportamentais em adolescentes ${ }^{18}$. No entanto, observa-se a centralização dos mapas, já no começo, mas principalmente, ao final da medida. No primeiro momento, apesar dos mapas aqui apresentados contarem com membros, de modo geral, próximos, as redes foram centralizadas nos quadrantes "amigos" e "família" do mapa. Este resultado vai ao encontro da pesquisa de Assis ${ }^{19}$, cujos sujeitos foram adolescentes infratores em regime deliberdade ou semiliberdade (do Rio de aneiro e dePernambuco), e que encontrou quea confiança da maioria dos entrevistados recai quase que exclusivamente sobre a família, aparecendo, em seguida, os amigos e Deus. Um único adolescente (Bernardo) preencheu o quadrante "comunidade", mas ainda assim, o fez esvaziado quando comparado aos demais quadrantes "família" e "amigos".

No segundo momento, a centralização na família tornou-se ainda mais evidente, sendo que o Júnior e o Tadeu resumiram seus mapas ao quadrante "família". No caso de Eduardo, o único membro inserido fora deste quadrante foi seu pai, que apesar de ser familiar, foi considerado um amigo, por ser separado da mãe e distante da família. Bernardo, ainda que não tenha aumentado o número de familiares em seu mapa, reduziu o número de membros nos demais quadrantes. $\mathrm{E}$ vale ressaltar que, ainda que ele tenha inserido membros no quadrante "amigos", estes claramente não são pares. N ota-se que justamente o jovem Bernardo que teve o melhor funcionamento familiar, bem como o mapa mais completo e com meIhor distribuição em ambos os momentos, foi 0 que apresentou o melhor desempenho na medida de ICPAE em ambos os momentos. Portanto, este resultado reforça o papel da rede social e da família como importantes fatores de proteção.

Entre todos os casos analisados, inicialmente, a importância da família - concluída pela ordem de inserção no mapa e pela proximidade com o jovem - estava centrada na figura da mãe (sempre a primeira lembrada) e dos irmãos, com um posicionamento paterno periférico. Quanto aosirmãos, ou foram trazidos todos para o mapa, ou apenas um mais velho, que parece assumir um papel de auxiliar da mãe no cuidado com os irmãos mais novos. No entanto, no segundo momento, a namorada e a mãe foram consideradas as figuras mais importantes, mesmo no caso de namoradas recentes, como a de Júnior.

Embora a família ainda seja a instituição que os jovens acreditam poder ajudá-los, esta mostrou-se extremamente fragilizada, vulnerável e com pouca capacidade de atuação. As notas de funcionamento familiar foram baixas, não passando de 61 .

Praticamente todos os jovens entrevistados falaram da influência dos pares na iniciativa do ato delinqüente, bem como do ressentimento com estes amigos, que só se apresentaram enquanto parceria para uso de drogas e para a prática de atos delinqüentes, mas que "sumiram" quando deste momento de dificuldade, com restrição da liberdade e afastamento da família. Ceolin ${ }^{7}$, ao avaliar o mapa da rede social de adolescentes infratores, encontrou um predomínio de pessoas no quadrante "amigos", o que, neste estudo, se verificou ape- 
nas no adolescente Bernardo. No entanto, naque la pesquisa, a amostra era deadolescentes que cumpriam PSC, não tendo privação de liberdade como os adolescentes do vigente estudo. Parece que naquele, os adolescentes estavam em um período anterior ao deste, em um período ainda de identificação e parceria com os amigos. Já neste momento deinternação, predominam a decepção com os pares e a desconfiança dos amigos. Esta desconfiança e afastamento dos pares se confirmam e se reforçam no segundo momento, em que três jovens afirmam não terem "companhias sociais" importantes, apenas Tadeu tendo citado alguém, ainda que a esposa, como exercendo este papel.

Embora a psiquiatra possa ter sido incluída para responder a uma expectativa imaginada pelo adolescente, já quea psiquiatra éuma das pesquisadoras, os monitores não estavam incluídos diretamente na pesquisa e desenvolvem um trabalho à parte do trabal ho da equipe da saúde. A lém disso, é bastante comum que os adolescentes façam críticas de um segmento da casa para outro (por exemplo, critiquem a monitoria para a equipetécnica, ou para o setor de saúde), o que torna ainda mais valioso o fato de os monitores terem sido lembrados e trazidos de forma positiva para uma psiquiatra da casa. Na primeira entrevista, a lembrança dos funcionários da Fasese deu umaúnica vez deforma voluntária, ainda que desta vez tenha sido feita de forma geral ("monitoria"). As lembranças denomes específicos ocorreram quando das seguintes perguntas: "Vocêprecisa recorrer a al guém quete ajude a colocar limites e a ver formas de solucionar conflitos com outros?" (quesito "regulação social"), além das questões "Quando você precisa de alguém que ajude a levantar o moral, quem o faz?" (quesito "apoio emocional") ou "quando vocêprecisa deconsel hos, a quem solicita?" (quesito "consel heiro"). Isso mostra mais claramente qual o papel que os funcionários da Fase têm exercido para estes jovens.

Comparando-se os dois momentos, observase um afastamento da Fase - seja como instituição ou representada por seus funcionários - do mapa destes jovens, o que é natural, considerando-se a redução do tempo de convívio. Bernardo representa a exceção ao trazer a Fase para o seu segundo mapa. No entanto, o queéalarmanteéo fato denão haver um enriquecimento do mapa a partir do convívio com aqueles sujeitos da comunidade. 0 movimento compensatório esperado de afastamento da instituição e de aproximação da comunidade, do trabalho, da escola e dos amigos, não se verificou. Com relação aos amigos, pode significar um distanciamento dos parceiros do crime, o que poderia ser encarado como um dado positivo, mas equanto às demais áreas? Talvez seis meses não seja um tempo suficiente para que se teçam estas novas teias da rede ou, pelo menos, para que se confie em seus novosintegrantes a ponto deconsiderá-los. Dequalquer forma, parece evidente tratar-se de um período especialmente vulnerável, em que esses jovens mostram sentirem-se sozinhos e, mesmo assim, é um período em que o Estado não oferece nenhum programa especial de acompanhamento, o que poderia explicar as altas taxas de reincidência. Ainda mais quando se observa que dois dos sujeitos aqui pesquisados consideraram não terem "ajuda material" ao final da medida, o que certamente incentiva o retorno à prática de assaltos e roubos. A necessidade desta atenção especial torna-seainda mais evidente quando se considera o desempenho na medida, já que a maioria das notas sofreu quedas ao longo do período, com exceção de Bernardo.

A droga, seja pelo seu uso, seja pela sua venda, esteve presente também na vida de três dos quatro adolescentes. Estes dados vão ao encontro dos estudos de Stouthamer-Loeber ${ }^{6}$, Windle ${ }^{9}$ e H usler ${ }^{10}$, e mostram a importância deste programa, aqui preconizado, visar, entre outros, à dependência química.

\section{Conclusões}

A intervenção psicossocial no adolescente ICPAE está claramente deficitária. Urge que se estabeleça um programa voltado especial mente para os adolescentes inseridos nesta condição.

Conclui-se o quão importanteéqueseimplantem medidas educativas elaborais mais significativas para esses internos, bem como que se desenvolvam atividades comunitárias. Essas os tornariam mais cientes do seu papel social, da repercussão da sua atitude na vida dos demais.

Também se ressalta a importância do resgate de uma figura paterna mais valorizada para estes internos. 0 acompanhamento familiar especializado poderia auxiliar neste processo, bem como na melhoria do funcionamento familiar desses jovens.

Os instrumentos aqui utilizados são de fácil aplicação, sendo que seu uso sistemático pelos técnicos da Fase poderia auxiliá-los, clareando a real condição psicossocial de cada adolescente, o que facilitaria inclusive a reflexão quanto ao benefício das saídas e o estabelecimento de prioridades em nível de intervenção. Faz-se necessário um trabaIho de assessoramento e instrumentalização dos profissionais da área.

Propõe-se que estudos posteriores possam utilizar estemesmo procedimento após o desligamen- 
to completo da instituição, de forma que se possa esclarecer como se comportam suas redes nesta nova etapa.

\section{Colaboradores}

BM Branco participou de toda a elaboração do artigo, concepção, delineamento, a análise e interpretação dos dados. A Wagner participou da redação do artigo, revisão crítica e aprovação da versão a ser publicada.

\section{Referências}

1. Valdés M, Serrano T, Rodríguez J, Roizblatt A, Florenzano $R$, Labra JF. Características del funcionamento familiar que predicen conductas de riesgo en adolescentes y sus famílias. Cuad M éd Soc 1997; XXXVIII (4):14-21.

2. Markiewicz $D$, Doyle $A B$, Brendgen $M$. The quality of adolescents'friendships: associations with mothers' interpersonal relationships, attachments to parents and friends, and prosocial behaviors. J Adolesc 2001; 24(4):429-445.

3. Laible DJ, Carlo G, Roesch SC. Pathways to self-esteem in late adolescence: the role of parent and peer attachment, empathy, and social behaviours. J Adolescence 2004; 27(6):703-716.

4. M CEIhaney KB, Immele A, Smith FD, Allen JP. Attachment organization as a moderator of the link between friendship quality and adolescent delinquency. Attach Hum Dev 2006; 8(1):33-46.

5. Caputo RK. Parent religiosity, family processes, and adolescent outcomes. Fam Soc 2004; 85(4):495-510.

6. Stouthamer-Loeber M, Wei E, Loeber R, Masten AS. Desistance from persistent serious delinquency in the transition to adulthood. Development and Psychopathology 2004; 16:897-918.

7. Ceolin L. A construção dos vínculos afetivos e sociais do adolescente em conflito com a lei [dissertação]. Porto Alegre (RS): Pontifícia Universidade Católica do Rio Grande do Sul; 2003.

8. Davis C, Tang C, Ko J. The impact of peer, family and school on delinquency. Int Social Work 2004; 47(4):489-502.

9. Windle M, Mason WA. General and specific predictors of behavioral and emotional problems among adolescents. J of Emotional and Behavioral Disorders 2004; 12(1):49-61.

10. Husler G, Plancherel B, Werlen E. Psychosocial predictors of cannabis use in adolescents at risk. Prev Sci 2005; 6(3):237-244.

11. Stake R. In: Denzin NK, Lincoln YS. Handbook of Qualitative Research. Thousand Oaks: Sage Publications; 2005

12. Sluzki CE. La red social: frontera de la pratica sistémica. Barcelona: Gedisa; 1996.

13. M eneses MPR. A construção de redes sócio-familiares de famílias imigrantes hispano-americanas [tese]. Porto Alegre (RS): Pontifícia Universidade Católica do Rio Grande do Sul; 2004.

14. Kaslow F. History, rationale and philosophic overview of issues and assumptions. In: Handbook of relational diagnosis and dysfunctional family patterns. N ew York: John Wiley \& Sons; 1996. 
15. Falceto OG, Busnello ED, Bozzetti EM C. Validação de escalas diagnósticas do funcionamento familiar para utilização em serviços de atenção primária à saúde. Rev Panamericana de Salud Pública/Pan Am J Pub Health 2000; 7(4):255-263.

16. Tucci AM, Kerr-Côrrea F, Dalben I. Ajuste social em pacientes com transtorno afetivo bipolar, unipolar, distimia e depressão dupla. Rev. Bras. Psiquiatr. 2001, 23(2):79-87.

17. Diretoria Sócio-Educativa da Fundação Estadual do Bem Estar do M enor/RS. Programa de Execução de M edidas Sócio-Educativas de Internação e Semiliberdade - PEM SEIS. Porto Alegre: Fase/RS; 2002.

18. Feinberg $M E$, Riggs NR, Greenberg $M T$. Social networks and community prevention coalitions. J Prim Prev 2005, 26(4):279-298.

19. Assis SG, Souza ER. Criando Caim e Abel - Pensando a prevenção da infração juvenil. Cienc Saude Colet 1999, 4(1):131-144.

Artigo apresentado em 06/01/2007

Aprovado em 08/08/2007

Versão final apresentada em 26/09/2007 